\title{
Hearing Status of Low-Income, Middle-Aged and Elderly Women in Northern China: A Population-Based, Cross-Sectional Study
}

Yi Xu, ${ }^{1, *}$ Jie Liu, $\mathbb{D}^{2-4, *}$ Chao Dong,' Sitong Guo,' Hui Cao,' Jing Zhang,' Mingxin Wang,' Jinghua Wang, (1D ${ }^{2-4}$ Xin $\mathrm{Li}, \mathbb{1 D}^{5}$ Dong Yang'

'Department of Otorhinolaryngology, Tianjin Medical University General Hospital, Tianjin, 300052, People's Republic of China; ${ }^{2}$ Department of Neurology, Tianjin Medical University General Hospital, Tianjin,

300052, People's Republic of China;

${ }^{3}$ Laboratory of Epidemiology, Tianjin

Neurological Institute, Tianjin, 300052,

People's Republic of China; ${ }^{4}$ Tianjin

Neurological Institute, Key Laboratory of

Post-Neuroinjury Neuro-Repair and Regeneration in Central Nervous System,

Ministry of Education and Tianjin City, Tianjin, 300052, People's Republic of China;

${ }^{5}$ Department of Otorhinolaryngology,

Beijing Tsinghua Changgung Hospital,School of Clinical Medicine, Tsinghua University,

Beijing, 102218, People's Republic of China

*These authors contributed equally to this work

Correspondence: Dong Yang

Department of Otorhinolaryngology,

Tianjin Medical University General

Hospital, I54 Anshan Road, Heping

District, Tianjin, 300052, People's

Republic of China

Tel +86-22-608I4958

$\mathrm{Fax}+86-22-60362400$

Email zyyentyd@163.com

Xin Li

Department of Otorhinolaryngology, Beijing Tsinghua Changgung Hospital, School of Clinical Medicine, Tsinghua University, No. 168, Litang Road,

Changping District, Beijing, 102218,

People's Republic of China

Tel +86 I3263358503

Fax +86-10-56II8969

Email entlixin@sina.com
Objective: Hearing impairment (HI) has become one of the most common causes of disability worldwide. To date, few studies have examined the hearing of women in these frequently rural regions. Thus, we explored the HI prevalence and risk factors among low-income, middle-aged, and elderly women in Tianjin, China.

Methods: Between October and November 2013, female residents aged $\geq 45$ years of rural Tianjin, China were recruited into the study. The participants completed questionnaire surveys, physical examinations, and hearing tests. The hearing at frequencies of $500 \mathrm{~Hz}, 1000 \mathrm{~Hz}, 2000$ $\mathrm{Hz}$, and $4000 \mathrm{~Hz}$ was used to analyze the hearing characteristics of specific frequency bands, and HI was defined as the better ear pure tone averages (PTA) $>25 \mathrm{~dB}$ HL.

Results: Among the 1416 participants, the prevalence of HI was $46.0 \%$. Among those aged 45-54-years, most $(65.3 \%)$ demonstrated normal hearing; in other age groups, slight $\mathrm{HI}$ accounted for the largest proportions of individuals. Compared with women who did not drink, the odds ratio (OR) of HI among women who consumed alcohol was 4.2 (95\% confidence interval [CI]: 1.844-9.574; $\mathrm{P}=0.001)$. Compared with pre-menopausal women, the OR of $\mathrm{HI}$ among postmenopausal women was 1.8 (95\% CI: 1.261-2.667; P = 0.001). Further, each 1-year increase in age in women resulted in a $7.1 \%$ increase in HI risk $(\mathrm{P}<$ 0.001).

Conclusion: The burden of HI among women is heavy in rural northern China, especially among those who experienced menopause. Additionally, the results suggest that to further reduce the risk of developing HI, women in rural areas should stop consuming alcohol. The problem of HI among women in rural areas should be taken seriously; moreover, the measures implemented to prevent HI in high-risk women should be strengthened.

Keywords: hearing impairment, women, risk factors, epidemiology, population-based study

\section{Introduction}

Globally, hearing impairment (HI) has become the third most common cause of disability in the elderly. ${ }^{1,2}$ As an age-related disease, $\mathrm{HI}$ accounts for almost $5 \%$ of the total years lived with disability ${ }^{3}$ and imposes a great burden on healthcare systems due to its long-term social, functional, and psychological complications. ${ }^{4}$ In 2018, there were approximately 466 million individuals with HI worldwide, ${ }^{5}$ with approximately $90 \%$ of those living in low- and middle-income countries. ${ }^{6}$ There are differences in hearing between men and women. ${ }^{7}$ In low-income countries or regions, women frequently have a lower social status than men. Therefore, more attention should be paid to hearing function in women. 
Previous studies indicated that the risk of $\mathrm{HI}$ is higher among postmenopausal women. ${ }^{8,9}$ Estrogen can be produced by auditory neurons, ${ }^{10}$ which can directly affect neurotransmission and indirectly affect cochlear blood flow. ${ }^{11,12}$ Regardless of the mechanism, few studies have focused on HI in rural women. Further, relevant population studies from China have not reported on the hearing abilities of rural women nor on the impact of menopause on the hearing of this population.

Thus, this study explored the hearing status of middleaged and elderly women in rural Tianjin, China and investigated factors affecting HI prevalence among these women.

\section{Methods}

\section{Study Population}

This population-based study was performed between September and November 2013 in rural Tianjin, China. The participants were recruited from the Tianjin Brain Study, which is a chronic disease surveillance study of low-income individuals, monitoring the chronic disease prevalence of long-term residents in the area since 1991. In brief, the participants were recruited from 18 administrative villages in rural Tianjin, China. Most (95\%) residents were low-income farmers with an annual per capita income of $<\$ 100$ US dollars (USD) in 1991 and $<\$ 2500$ USD in $2018 .{ }^{13}$ All women aged over 45 years who live in Yangjinzhuang Town, Jizhou District, Tianjin were qualified in this study. Those women who worked out of Tianjin, or were disability due to diseases, were excluded in this study.

\section{Information Collection and Risk Factor Definition}

The data for this study were obtained and recorded by trained researchers using face-to-face interviews. Demographic information, including participant sex, age, and educational level, were captured using pre-designed questionnaires. The participants were grouped into four age categories: 45-54 years, 55-64 years, 65-74 years, and $\geq 75$ years. Participant educational levels were classified into three groups, based on their years of formal education: illiterate ( 0 years), $1-6$ years, and $>6$ years.

Individual and family medical histories, including information regarding hypertension, diabetes mellitus (DM), stroke, and coronary heart disease (CHD), were obtained from participant self-reports or existing medical records. Cigarette smoking was defined as smoking $>1$ cigarette/day for $\geq 1$ year; participants were categorized as non-smokers, current smokers, or previous smokers. Alcohol consumption was defined as drinking one alcoholic beverage/week for $\geq 1$ year; participants were categorized as non-drinkers, past drinkers, or current drinkers. Data regarding eating habits and menopause details were obtained through participant self-reports.

\section{Physical Examination}

Systolic blood pressure (SBP), diastolic blood pressure (DBP), height, weight, waist circumference, and hip circumference measurements were performed by local general practitioners. Further, fasting levels of blood glucose (FBG), total cholesterol (TC), triglycerides (TG), highdensity lipoprotein cholesterol (HDL-C), and low-density lipoprotein cholesterol (LDL-C) were determined within 2 hours after the blood sample was taken at the Jizhou People's Hospital (Tianjin, China), which has an international standard blood laboratory with reliable test results. Body mass index (BMI) was calculated as the individual's weight $(\mathrm{kg})$ divided by the square of their height $\left(\mathrm{m}^{2}\right)$; weight classifications were based on BMI (low-weight, $<18.5 \mathrm{~kg} / \mathrm{m}^{2}$; normal, $18.5-23.9 \mathrm{~kg} / \mathrm{m}^{2}$; overweight, $24.0-27.9 \mathrm{~kg} / \mathrm{m}^{2}$; and obese, $\left.\geq 28.0 \mathrm{~kg} / \mathrm{m}^{2}\right) .{ }^{14}$

\section{Hearing Test}

Professional otolaryngology medical technicians performed bilateral otoscopy and audiometry evaluations on each participant in a quiet, soundproof room; participants with suspected HI were referred to audiologists for final diagnoses. Air conduction hearing thresholds at $500 \mathrm{~Hz}$, $1000 \mathrm{~Hz}, 2000 \mathrm{~Hz}$, and $4000 \mathrm{~Hz}$ frequencies were obtained using a Denmark Xeta Audiometer (EN60645-1, type 3). When measuring the hearing of one ear, masking was used on the other ear. Hearing at frequencies of 500 $\mathrm{Hz}, 1000 \mathrm{~Hz}, 2000 \mathrm{~Hz}$, and $4000 \mathrm{~Hz}$ was used to analyze the hearing characteristics of specific frequency bands.

Pure tone averages (PTAs), representing speech frequencies and reported as decibels of hearing level $(\mathrm{dB}$ $\mathrm{HL}$ ), were calculated using the average audiometric thresholds of $500 \mathrm{~Hz}, 1000 \mathrm{~Hz}, 2000 \mathrm{~Hz}$, and $4000 \mathrm{~Hz}$ for the bilateral ears. HI was defined as the better PTA $>25$ $\mathrm{dB}$ HL; and HI was stratified using the bilateral PTA results as slight $(>25$ and $\leq 40 \mathrm{~dB} \mathrm{HL})$, moderate ( $>40$ and $\leq 60 \mathrm{~dB} \mathrm{HL}$ ), severe ( $>60$ and $\leq 80 \mathrm{~dB} \mathrm{HL}$ ), and severe to profound $(>80 \mathrm{~dB} \mathrm{HL}) .{ }^{15} \mathrm{HI}$ was defined based on the better hearing ear (using PTA). 


\section{Statistical Analyses}

Continuous variables (age, BMI, SBP, DBP, WHR, FBG, TC, TG, HDL-C, LDL-C, and PTA) are presented as means and standard deviations; between-group comparisons of these values were performed using Student's $t$-tests. Categorical variables of age group; education group; BMI group; smoking history; alcohol consumption history; and previous histories of hypertension, DM, stroke, and CHD are presented as number of patients and prevalence. The between-group comparisons for categorical variables were performed using the chi-squared test. Binary logistic regression was chosen to evaluate the association between $\mathrm{HI}$ and its potential risk factors. In the multivariate analysis, we selected variables that had $P$ values $<0.05$ in two-tailed tests in univariate analysis. Finally, the dependent variable was binary (HI or normal hearing), and the independent variables were education group, alcohol consumption history, menopause history, age, and SBP. Moreover, multivariate analysis results are presented as odds ratios (ORs) with $95 \%$ confidence intervals (CIs). All analyses were conducted using SPSS for Windows (version 25.0; SPSS, Chicago, IL, USA); P < 0.05 was considered statistically significant.

\section{Results}

Total of 1881 participants were recruited among 2452 permanent women after excluded those worked outside residents $(n=200)$, disability due to diseases $(n=59)$. Of these, 1416 women finished the hearing test. As menopausal history was included in the multivariate analysis, 81 (5.7\%) women with missing menstrual history data were excluded from the model. Finally, 1335 participants were assessed the prevalence and risk factors of HI.

\section{Patient Demographics}

Of the 1416 included women, 652 (46.0\%) demonstrated HI, $617(44.4 \%)$ were illiterate, 588 (41.5\%) had hypertension, 143 (10.1\%) had DM, and 220 (15.6\%) had CHD (Table 1).

\section{Factors Associated with $\mathrm{HI}$ in the Univariate Analysis}

The prevalence of HI increased significantly with increasing age, but decreased with increasing levels of education (both, $\mathrm{P}<0.001$ ). The HI prevalence was higher among women who consumed alcohol than among those who did not and among menopausal women than among premenopausal women (both, $\mathrm{P}<0.001$ ). The mean menopausal age and DBP were significantly lower in participants with $\mathrm{HI}$ than in those without HI (both, $\mathrm{P}<0.05$ ); however, mean SBP was significantly higher in participants with $\mathrm{HI}$ $(\mathrm{P}=0.001)($ Table 1).

\section{Hearing Test Results, by Age}

With increasing age, the percentage of participants with normal hearing declined; the prevalence of moderate, severe, and extremely severe HI was significantly higher in the older age groups than in the 45-54-years-old group (all, $\mathrm{P}<0.001$ ). In addition to right ear $\mathrm{HI}$ at $500 \mathrm{~Hz}$, the percentage of patients with bilateral $\mathrm{HI}$ at $1000 \mathrm{~Hz}, 2000$ $\mathrm{Hz}, 4000 \mathrm{~Hz}$, and PTA increased with age (all, $\mathrm{P}<0.001$ ) (Table 2).

\section{Factors Associated with $\mathrm{HI}$ in the Multivariate Analysis}

After adjusting for education and SBP, older age, alcohol consumption, and menopausal history were independent risk factors for $\mathrm{HI}$ (all, $\mathrm{P}<0.05$ ). The prevalence of $\mathrm{HI}$ was 4.2-fold higher among women who consumed alcohol than among women who never did so (95\% CI: 1.840 9.556; $\mathrm{P}=0.001)$. Compared with premenopausal women, the OR of HI among postmenopausal women was 1.8 (95\% CI: 1.261-2.677; $\mathrm{P}=0.001$ ); each 1-year increase in age resulted in $7.1 \%$ decrease in the risk of $\mathrm{HI}(\mathrm{P}<$ 0.001) (Table 3).

\section{Discussion}

This large-scale population study explored the hearing status of women aged $\geq 45$ years who resided in a rural area of northern China. The HI prevalence among the study population was $46.0 \%$ and increased with increasing age. In addition, the OR for developing HI was 4.2-fold higher for women who consumed alcohol than for those who did not. Postmenopausal women were 1.8 times more likely to develop HI than were premenopausal women.

A previous study reported that in the United States, the prevalence of HI was $28.5 \%$ among women $\geq 55$ years old. ${ }^{16}$ Similarly, a study conducted in the Netherlands showed that the prevalence of HI was $29 \%$ among female participants $\geq 65$ years old. ${ }^{17}$ In Finland, a populationbased HI study involving 55-64-year-old adults reported that the prevalence of $\mathrm{HI}$ was $18.4 \% .{ }^{18}$ However, the prevalence of $\mathrm{HI}$ among $\geq 65$ years old women in Brazil was $39.4 \%,{ }^{19}$ and the total prevalence of $\mathrm{HI}$ was $38.8 \%$ in rural India, ${ }^{20}$ which was much higher than that in 
Table I Associated Factors of Hearing Impairment in the Univariate Analysis

\begin{tabular}{|c|c|c|c|c|}
\hline Category & Total & Normal Hearing & Hearing Impairment & $\mathbf{P}$ \\
\hline Total: & 1416 & $764(54.0)$ & $652(46.0)$ & \\
\hline Age group, n (\%) & & & & $<0.001$ \\
\hline $45 \sim 54$ years & $123(8.7)$ & $25(3.3)$ & $98(15.0)$ & \\
\hline $55 \sim 64$ years & $325(23.0)$ & $139(18.2)$ & $186(28.5)$ & \\
\hline $65 \sim 74$ years & $591(4 I .7)$ & $354(46.3)$ & $237(36.3)$ & \\
\hline$\geq 75$ years & $377(26.6)$ & $246(32.2)$ & $|3|(20.1)$ & \\
\hline Education*, n (\%) & & & & $<0.001$ \\
\hline 0 years & $617(44.4)$ & $293(39.1)$ & $324(50.5)$ & \\
\hline $1 \sim 6$ years & $399(28.7)$ & $214(28.6)$ & $185(28.8)$ & \\
\hline$>6$ years & $275(19.8)$ & $242(32.3)$ & $133(20.7)$ & \\
\hline Menopause*, n (\%) & & & & $<0.001$ \\
\hline No & $215(16.1)$ & $134(62.3)$ & 81 (37.7) & \\
\hline Yes & $1120(83.9)$ & $589(52.3)$ & $531(47.4)$ & \\
\hline Smoking status, n (\%) & & & & 0.372 \\
\hline Never smoking & $1356(95.8)$ & $735(54.2)$ & $621(45.8)$ & \\
\hline Now or ever smoking & $60(4.2)$ & $29(48.3)$ & $31(5 \mid .7)$ & \\
\hline Alcohol consumption, n (\%) & & & & $<0.001$ \\
\hline Never drinking & $1380(97.4)$ & 755 (54.7) & $625(45.3)$ & \\
\hline Now or ever drinking & $36(2.6)$ & $9(25.0)$ & $27(75.0)$ & \\
\hline Stroke, n (\%) & & & & 0.999 \\
\hline No & $1340(94.6)$ & $723(54)$ & $617(46)$ & \\
\hline Yes & $76(5.4)$ & $4 \mid(53.9)$ & $35(46.1)$ & \\
\hline Hypertension, n (\%) & & & & 0.152 \\
\hline No & $828(58.5)$ & $460(55.6)$ & $368(44.4)$ & \\
\hline Yes & $588(41.5)$ & $304(51.7)$ & $284(48.3)$ & \\
\hline High-carbohydrate diet, n (\%) & & & & $0.08 I$ \\
\hline No & $1376(97.2)$ & $737(53.6)$ & $639(46.4)$ & \\
\hline Yes & $40(2.8)$ & $27(67.5)$ & $13(32.5)$ & \\
\hline Diabetes, n (\%) & & & & 0.205 \\
\hline No & $1273(89.9)$ & $694(90.8)$ & $579(88.8)$ & \\
\hline Yes & $143(10.1)$ & $70(9.2)$ & $73(11.2)$ & \\
\hline CHD, n (\%) & & & & 0.085 \\
\hline No & $1196(84.4)$ & $657(54.9)$ & $539(45.1)$ & \\
\hline Yes & $220(15.6)$ & $107(48.6)$ & $113(51.4)$ & \\
\hline BMI, n (\%) & & & & 0.173 \\
\hline Low-weight & $265(4.6)$ & $142(53.6)$ & $123(46.4)$ & \\
\hline Normal & $561(39.6)$ & $317(56.5)$ & $244(43.5)$ & \\
\hline Overweight & $42(3.0)$ & $17(40.5)$ & $25(59.5)$ & \\
\hline Obesity, n (\%) & $548(38.7)$ & $288(52.6)$ & $260(47.4)$ & \\
\hline Age, means (SD), years & $60.83(9.04)$ & $58.69(7.60)$ & $63.34(9.92)$ & $<0.001$ \\
\hline BMI, means (SD), $\mathrm{Kg} / \mathrm{m}^{2}$ & $24.91(3.67)$ & $24.99(3.50)$ & $24.82(3.85)$ & 0.405 \\
\hline WHR, means (SD) & $0.90(0.26)$ & $0.89(0.06)$ & $0.91(0.38)$ & 0.191 \\
\hline Menopause age, $\mathrm{mmol} / \mathrm{L}$ & $49.18(4.11)$ & $49.44(3.82)$ & $48.89(4.40)$ & 0.025 \\
\hline
\end{tabular}

(Continued) 
Table I (Continued).

\begin{tabular}{|c|c|c|c|c|}
\hline Category & Total & Normal Hearing & Hearing Impairment & $\mathbf{P}$ \\
\hline FBG, means (SD), mmol/L & $5.54(1.8 I)$ & $5.5(1.76)$ & $5.58(1.86)$ & 0.373 \\
\hline $\mathrm{TC}$, means (SD), mmol/L & $4.78(0.94)$ & $4.75(0.93)$ & $4.82(0.95)$ & 0.143 \\
\hline TG, means (SD), mmol/L & $1.58(0.97)$ & $1.59(0.96)$ & I.57 (0.97) & 0.756 \\
\hline HDL-C, means (SD), mmol/L & $\mathrm{I} .40(0.46)$ & $1.39(0.43)$ & I.4I (0.49) & 0.302 \\
\hline LDL-C, means (SD), mmol/L & $2.71(0.85)$ & $2.69(0.84)$ & $2.75(0.86)$ & 0.180 \\
\hline SBP, means (SD), mmHg & $151.57(24.04)$ & I49.57 (23.73) & $153.9(24.22)$ & 0.001 \\
\hline DBP, means (SD), mmHg & $90.55(12.36)$ & $91.21(12.12)$ & 89.77 (12.59) & 0.030 \\
\hline
\end{tabular}

Note: *Presented data with missing case for education $(n=25)$ and menopause $(n=81)$.

Abbreviations: SD, standard deviation; SBP, systolic blood pressure; DBP, diastolic blood pressure; BMI, body mass index; FBG, fasting blood glucose; TC, total cholesterol; TG, triglycerides; HDL-C, high density lipoprotein cholesterol; LDL-C, low density lipoprotein cholesterol.

Table 2 Hearing Test Results and Hearing Grading of Women by Age Groups

\begin{tabular}{|c|c|c|c|c|c|}
\hline Category & 45-54 Years & 55-64 Years & 65-74 Years & $\geq 75$ Years & $\mathbf{P}$ \\
\hline $\begin{array}{l}\text { Hearing classification, } \\
\text { n (\%): } \\
\text { Normal } \\
\text { Slight } \\
\text { Moderate } \\
\text { Severe }\end{array}$ & $\begin{array}{c}246(65.3) \\
126(33.4) \\
5(1.3) \\
-\end{array}$ & $\begin{array}{c}354(59.9) \\
210(35.5) \\
26(4.4) \\
1(0.2)\end{array}$ & $\begin{array}{c}139(42.8) \\
156(48.0) \\
27(8.3) \\
3(0.9)\end{array}$ & $\begin{array}{c}25(20.3) \\
61(49.6) \\
35(28.5) \\
2(1.6)\end{array}$ & $<0.001$ \\
\hline \multicolumn{6}{|l|}{$\begin{array}{l}\text { Hearing test }(\mathrm{dBHL}) \text {, } \\
\text { means(SD): }\end{array}$} \\
\hline L $500 \mathrm{~Hz}$ & $28.16(9.86)$ & $28.67(9.85)$ & $31.48(12.15)$ & $35.73(14.48)$ & $<0.001$ \\
\hline L $1000 \mathrm{~Hz}$ & $27.37(9.59)$ & $28.64(10.12)$ & $32.08(13.24)$ & 36.79 (13.72) & $<0.001$ \\
\hline L $2000 \mathrm{~Hz}$ & $26.29(8.19)$ & $27.64(9.33)$ & $31.92(13.08)$ & $37.52(15.11)$ & $<0.001$ \\
\hline $\mathrm{L} 4000 \mathrm{~Hz}$ & $26.59(8.39)$ & $29.85(23.90)$ & 34.23 (15.39) & $44.76(18.38)$ & $<0.001$ \\
\hline R $500 \mathrm{~Hz}$ & $27.32(8.64)$ & $27.78(10.40)$ & $41.58(194.56)$ & $37.64(31.92)$ & 0.057 \\
\hline R $1000 \mathrm{~Hz}$ & $27.27(8.27)$ & $28.47(11.66)$ & $31.58(13.16)$ & $37.44(13.90)$ & $<0.001$ \\
\hline R $2000 \mathrm{~Hz}$ & $25.74(7.45)$ & $27.32(11.36)$ & $31.72(17.52)$ & $38.66(14.40)$ & $<0.001$ \\
\hline $\mathrm{R} 4000 \mathrm{~Hz}$ & $26.21(8.79)$ & $28.69(12.00)$ & $33.86(15.15)$ & $44.02(17.40)$ & $<0.001$ \\
\hline RPTA & $26.63(7.47)$ & $28.06(10.49)$ & $34.69(50.36)$ & $39.44(14.63)$ & $<0.001$ \\
\hline LPTA & $27.10(8.35)$ & $28.70(10.66)$ & $32.43(12.40)$ & $38.70(14.07)$ & $<0.001$ \\
\hline
\end{tabular}

developed countries. Previous studies have indicated that the level of economic development affects the prevalence of HI. ${ }^{16,17}$ Socioeconomic status has been confirmed to be a main factor predicting HI prevalence. ${ }^{4,21-23}$ From previous studies, it can be found that the prevalence of $\mathrm{HI}$ in developed countries is much lower than in developing countries. ${ }^{8,17}$ Moreover, study populations from different regions have different living and eating habits that need to be considered more in depth to determine their effect on hearing. Thus, this may explain why the prevalence of HI among the rural women reported in this study was higher than that reported in more developed areas.
Between 1980 and 2010, as the global population has aged, the prevalence of $\mathrm{HI}$ in developed countries has doubled. ${ }^{24}$ Previous studies have indicated that $\mathrm{HI}$ is an age-related disease. ${ }^{25-27}$ Similarly, in this study, the values of the pure-tone hearing tests increased with increasing age, and the risk of developing $\mathrm{HI}$ also increased with age. Prior studies have shown that mitochondrial DNA mutations ${ }^{28}$ and oxidative damage ${ }^{29}$ are mechanisms contributing to $\mathrm{HI}$ in aging people.

Controversy exists about the relationship between alcohol consumption and HI. One previous study reported that drinking increases the risk of $\mathrm{HI}^{30}{ }^{30}$ while others either 
Table 3 Adjusted OR (95\% Cl) of Risk Factors Association with Hearing Impairment

\begin{tabular}{|c|c|c|}
\hline Risk Factors & OR (95\% CI) & $\mathbf{P}$ \\
\hline \multicolumn{3}{|l|}{ Education groups: } \\
\hline 0 years & I.24I (0.910, I.692) & 0.172 \\
\hline I $\sim 6$ years & I.I84 (0.863, I.625) & 0.295 \\
\hline$>6$ years & 1.00 & - \\
\hline \multicolumn{3}{|l|}{ Alcohol consumption } \\
\hline No & 1.00 & - \\
\hline Yes & $4.202(1.844,9.574)$ & 0.001 \\
\hline \multicolumn{3}{|l|}{ Menopause history } \\
\hline No & 1.00 & - \\
\hline Yes & I.834 (I.26I, 2.667) & 0.001 \\
\hline Age & I.07I (1.052, I.090) & $<0.001$ \\
\hline SBP & $1.002(0.997,1.007)$ & 0.504 \\
\hline
\end{tabular}

indicated a U-shaped association between alcohol consumption and $\mathrm{HI}^{31,32}$ or did not find a significant association. ${ }^{33,34}$ The present study showed that the prevalence of HI was significantly higher among women who consumed alcohol than among those who never consumed alcohol. The mechanism for alcohol consumption's effect on hearing is unclear, and further research is needed.

The relationship between menopause and HI is also unclear. Although some studies have shown that ovarian hormones, including estrogen, may have a negative effect on the cochlear nerve, ${ }^{35}$ most studies have reported that estrogen exerts a protective effect on hearing. ${ }^{36,37}$ Previous studies have also demonstrated the expression of estrogen in the inner ear. ${ }^{10}$ Moreover, estrogen can be produced by auditory neurons per se and directly affects neurotransmission. ${ }^{11}$ In addition, estrogen has also been shown to indirectly affect cochlear blood flow, which may play a role in auditory function. ${ }^{12}$ In this study, compared with premenopausal women, the prevalence of HI increased among postmenopausal women. The mechanism by which menopause may impact HI remains unclear, and more research is needed to strengthen the conclusions.

The impact of blood pressure on $\mathrm{HI}$ is also inconclusive. Some studies have indicated that hypertension is a risk factor for $\mathrm{HI},{ }^{38,39}$ while another study reported no significant relationship between SBP and HI. ${ }^{40}$ Another study showed that the relationship between age-related hearing loss and blood pressure differs according to age. There is no correlation between blood pressure and hearing in women aged 70-75 years, but in women aged over
79 years, there is a high correlation between SBP and lowfrequency hearing loss. ${ }^{41}$ In the present study, a significant relationship between SBP and HI was not observed. Further, the mechanism by which blood pressure may impact HI remains unclear. High blood pressure may harm hearing due to pressure-induced microvascular atherosclerosis, which affects the auditory blood flow and causes hearing loss. ${ }^{36}$ Long-term follow-up studies are required to validate this relationship.

This study has some limitations. First, this was a single-center study and a multi-center study is needed to verify the present results. Second, due to the lack of the exact amount of alcohol consumed within a certain period, we used categorical variables to evaluate the impact of alcohol consumption on HI. The relationship between the amount of alcohol consumed and any associated HI needs further exploration. Third, this study did not employ otoscopy and tympanometry test on patients because the conditions of the study were limited. In the follow-up, we will implement more rigorous hearing-related testing. Finally, as this was a cross-sectional study, causal relationships between the risk factors and HI cannot be determined; follow-up studies involving similar populations are required.

\section{Conclusion}

This was the first large-scale population study to investigate the hearing status of rural women $\geq 45$ years old in northern China. There is a substantial burden of HI among women in rural northern China. Alcohol consumption and older age appear to increase the prevalence of $\mathrm{HI}$. Moreover, postmenopausal women have a significantly increased prevalence of HI. Therefore, targeted health guidance should be formulated regarding the factors influencing $\mathrm{HI}$ to reduce the prevalence of $\mathrm{HI}$ among women residing in rural areas of northern China; in particular, attention should be given to postmenopausal women.

\section{Abbreviations}

HI, hearing impairment; DM, diabetes mellitus; CHD, coronary heart disease; SBP, systolic blood pressure; DBP, diastolic blood pressure; FBG, fasting levels of blood glucose; TC, total cholesterol; TG, triglycerides; HDL-C, high-density lipoprotein cholesterol; LDL-C, lowdensity lipoprotein cholesterol; BMI, body mass index; PTA, pure tone average; SD, standard deviation; OR, odds ratio. 


\section{Data Sharing Statement}

The datasets generated during and/or analyzed during the current study are available from the corresponding author on reasonable request.

\section{Ethics Approval and Informed Consent}

The study was approved by the ethics committee of Tianjin Medical University General Hospital; informed consent was obtained from each participant. This study was conducted in accordance with the Declaration of Helsinki.

\section{Acknowledgments}

We thank all participants of the Tianjin Brain Study, and local medical care professionals for their valuable contributions.

\section{Author Contributions}

All authors made a significant contribution to the work reported, whether that is in the conception, study design, execution, acquisition of data, analysis and interpretation, or in all these areas; took part in drafting, revising or critically reviewing the article; gave final approval of the version to be published; have agreed on the journal to which the article has been submitted; and agree to be accountable for all aspects of the work.

\section{Funding}

There is no funding to report.

\section{Disclosure}

The authors declare that they have no competing interests.

\section{References}

1. World report on disability. Available from: https://www.who.int/ health-topics/disability. Accessed September 7, 2021.

2. Kiely KM, Gopinath B, Mitchell P, Luszcz M, Anstey KJ. Cognitive, health, and sociodemographic predictors of longitudinal decline in hearing acuity among older adults. J Gerontol A Biol Sci Med Sci. 2012;67(9):997-1003. doi:10.1093/gerona/gls066

3. World Health Organization. Addressing the rising prevalence of hearing loss. Available from: http://www.who.int/pbd/deafness/estimates/ en/. Accessed September 7, 2021.

4. Cruickshanks KJ, Nondahl DM, Tweed TS, et al. Education, occupation, noise exposure history and the 10-yr cumulative incidence of hearing impairment in older adults. Hear Res. 2010;264(1-2):3-9. doi:10.1016/j.heares.2009.10.008

5. GBD 2017 Disease and Injury Incidence and Prevalence Collaborators. Global, regional, and national incidence, prevalence, and years lived with disability for 354 diseases and injuries for 195 countries and territories, 1990-2017: a systematic analysis for the Global Burden of Disease Study 2017. Lancet. 2018;392 (10159):1789-1858. doi:10.1016/S0140-6736(18)32279-7
6. Davis AC, Hoffman HJ. Hearing loss: rising prevalence and impact. Bull World Health Organ. 2019;97(10):646. doi:10.2471/ BLT.19.224683

7. Pearson JD, Morrell CH, Gordon-Salant S, et al. Gender differences in a longitudinal study of age-associated hearing loss. J Acoust Soc Am. 1995;97(2):1196-1205. doi:10.1121/1.412231

8. Caruso S, Maiolino L, Agnello C, Garozzo A, Di Mari L, Serra A. Effects of patch or gel estrogen therapies on auditory brainstem response in surgically postmenopausal women: a prospective, randomized study. Fertil Steril. 2003;79(3):556-561. doi:10.1016/S00150282(02)04763-5

9. Khaliq F, Tandon OP, Goel N. Auditory evoked responses in postmenopausal women on hormone replacement therapy. Indian J Physiol Pharmacol. 2003;47(4):393-399.

10. Stenberg AE, Wang H, Fish J, Schrott-Fischer A, Sahlin L, Hultcrantz M. Estrogen receptors in the normal adult and developing human inner ear and in Turner's syndrome. Hear Res. 2001;157(12):87-92. doi:10.1016/S0378-5955(01)00280-5

11. Pinaud R, Tremere LA. Control of central auditory processing by a brain-generated oestrogen. Nat Rev Neurosci. 2012;13(8):521-527. doi: $10.1038 / \mathrm{nrn} 3291$

12. Laugel GR, Dengerink HA, Wright JW. Ovarian steroid and vasoconstrictor effects on cochlear blood flow. Hear Res. 1987;31 (3):245-251. doi:10.1016/0378-5955(87)90194-8

13. China statistical yearbook 2019; 2019. Available from: http://www. stats.gov.cn/tjsj/ndsj/. Accessed September 7, 2021.

14. Zhou BF. Effect of body mass index on all-cause mortality and incidence of cardiovascular diseases-report for meta-analysis of prospective studies open optimal cut-off points of body mass index in Chinese adults. Biomed Environ Sci. 2002;15(3):245-252.

15. World Health Organization. Grades of hearing impairment. Prevention of blindness and deafness; 1997. Available from: https://www.who.int/pbd/deafness/hearing_impairment_grades/en/. Accessed September 7, 2021.

16. Fischer ME, Cruickshanks KJ, Pinto A, Klein BE, Klein R, Dalton DS. Hearing impairment and retirement. $J$ Am Acad Audiol. 2014;25(2):164-170. doi:10.3766/jaaa.25.2.5

17. Homans NC, Metselaar RM, Dingemanse JG, et al. Prevalence of age-related hearing loss, including sex differences, in older adults in a large cohort study. Laryngoscope. 2017;127(3):725-730. doi:10.1002/lary.26150

18. Hannula S, Mäki-Torkko E, Majamaa K, Sorri M. Hearing in a 54- to 66-year-old population in northern Finland. Int J Audiol. 2010;49 (12):920-927. doi:10.3109/14992027.2010.510146

19. Mattos LC, Veras RP. The prevalence of hearing loss in an elderly population in Rio de Janeiro: a cross-sectional study. Braz $J$ Otorhinolaryngol. 2007;73(5):654-659. doi:10.1016/S18088694(15)30126-9

20. Garg S, Kohli C, Mangla V, Chadha S, Singh MM, Dahiya N. An epidemiological study on burden of hearing loss and its associated factors in Delhi, India. Ann Otol Rhinol Laryngol. 2018;127 (9):614-619. doi:10.1177/0003489418781968

21. Luo Y, Gao J, Zheng X. Individual-level and area-level socioeconomic inequalities in hearing impairment among Chinese adults: a population-based study. J Epidemiol Community Health. 2020;74 (6):541-547. doi:10.1136/jech-2019-213437

22. Emmett SD, Francis HW. The socioeconomic impact of hearing loss in U.S. adults. Otol Neurotol. 2015;36(3):545-550. doi:10.1097/ MAO. 0000000000000562

23. Ramsey T, Svider PF, Folbe AJ. Health burden and socioeconomic disparities from hearing loss: a global perspective. Otol Neurotol. 2018;39(1):12-16. doi:10.1097/MAO.0000000000001630

24. Knipper M, Van Dijk P, Nunes I, Rüttiger L, Zimmermann U. Advances in the neurobiology of hearing disorders: recent developments regarding the basis of tinnitus and hyperacusis. Prog Neurobiol. 2013;111:17-33. doi:10.1016/j.pneurobio.2013.08.002 
25. Stevens KN, Lang IA, Guralnik JM, Melzer D. Epidemiology of balance and dizziness in a national population: findings from the English Longitudinal Study of Ageing. Age Ageing. 2008;37 (3):300-305. doi:10.1093/ageing/afn019

26. Yamasoba T, Lin FR, Someya S, Kashio A, Sakamoto T, Kondo K. Current concepts in age-related hearing loss: epidemiology and mechanistic pathways. Hear Res. 2013;303:30-38. doi:10.1016/j. heares.2013.01.021

27. Park HJ, Yoo MH, Woo SY, Kim SW, Cho YS. Prevalence of hearing loss and associated factors in subjects with normal otoscopy: a national cross-sectional study. Int J Audiol. 2017;56(12):951-957. doi:10.1080/14992027.2017.1373866

28. Kujoth GC, Hiona A, Pugh TD, et al. Mitochondrial DNA mutations, oxidative stress, and apoptosis in mammalian aging. Science. 2005;309(5733):481-484. doi:10.1126/science.1112125

29. Someya S, Xu J, Kondo K, et al. Age-related hearing loss in C57BL/ $6 \mathrm{~J}$ mice is mediated by Bak-dependent mitochondrial apoptosis. Proc Natl Acad Sci U S A. 2009;106(46):19432-19437. doi:10.1073/ pnas.0908786106

30. Rosenhall U, Sixt E, Sundh V, Svanborg A. Correlations between presbyacusis and extrinsic noxious factors. Audiology. 1993;32 (4):234-243. doi:10.3109/00206099309072939

31. Gopinath B, Flood VM, McMahon CM, Burlutsky G, Smith W, Mitchell P. The effects of smoking and alcohol consumption on age-related hearing loss: the Blue Mountains Hearing Study. Ear Hear. 2010;31(2):277-282. doi:10.1097/AUD.0b013e3181c8e902

32. Fransen E, Topsakal V, Hendrickx JJ, et al. Occupational noise, smoking, and a high body mass index are risk factors for age-related hearing impairment and moderate alcohol consumption is protective: a European population-based multicenter study. $J$ Assoc Res Otolaryngol. 2008;9(3):264-276. doi:10.1007/s10162-008-0123-1
33. Brant LJ, Gordon-Salant S, Pearson JD, et al. Risk factors related to age-associated hearing loss in the speech frequencies. $J$ Am Acad Audiol. 1996;7(3):152-160.

34. Curhan SG, Eavey R, Wang M, Stampfer MJ, Curhan GC. Prospective study of alcohol consumption and self-reported hearing loss in women. Alcohol. 2015;49(1):71-77. doi:10.1016/j. alcohol.2014.10.001

35. Willott JF. Effects of sex, gonadal hormones, and augmented acoustic environments on sensorineural hearing loss and the central auditory system: insights from research on C57BL/6J mice. Hear Res. 2009;252(1-2):89-99. doi:10.1016/j.heares.2008.12.002

36. Trott S, Cline T, Weihing J, Beshear D, Bush M, Shinn J. Hormones and hearing: central auditory processing in women. $\mathrm{J} \mathrm{Am} \mathrm{Acad}$ Audiol. 2019;30(6):493-501. doi:10.3766/jaaa.17123

37. Orendorz-Frączkowska K, Temporale H. Organ of hearing and balance in peri- and postmenopausal women. Effects of hormone replacement therapy on hearing and balance in peri- and post-menopausal women: the current state of knowledge. Adv Clin Exp Med. 2020;29 (6):751-755. doi:10.17219/acem/121935

38. Gates GA, Cobb JL, D'Agostino RB, Wolf PA. The relation of hearing in the elderly to the presence of cardiovascular disease and cardiovascular risk factors. Arch Otolaryngol Head Neck Surg. 1993;119(2):156-161. doi:10.1001/archotol.1993.01880140038006

39. Reed NS, Huddle MG, Betz J, et al. Association of midlife hypertension with late-life hearing loss. Otolaryngol Head Neck Surg. 2019;161(6):996-1003. doi:10.1177/0194599819868145

40. Fischer ME, Schubert CR, Nondahl DM, et al. Subclinical atherosclerosis and increased risk of hearing impairment. Atherosclerosis. 2015;238(2):344-349. doi:10.1016/j.atherosclerosis.2014.12.031

41. Rosenhall U, Sundh V. Age-related hearing loss and blood pressure. Noise Health. 2006;8(31):88-94. doi:10.4103/1463-1741.33539
Journal of Multidisciplinary Healthcare

\section{Publish your work in this journal}

The Journal of Multidisciplinary Healthcare is an international, peerreviewed open-access journal that aims to represent and publish research in healthcare areas delivered by practitioners of different disciplines. This includes studies and reviews conducted by multidisciplinary teams as well as research which evaluates the results or conduct of such teams or healthcare processes in general. The journal

\section{Dovepress}

covers a very wide range of areas and welcomes submissions from practitioners at all levels, from all over the world. The manuscript management system is completely online and includes a very quick and fair peer-review system. Visit http://www.dovepress.com/testimonials. php to read real quotes from published authors. 